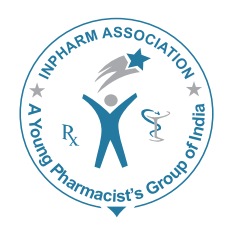

\title{
JIYP
}

\section{Litsea Deccanensis Ameliorates Myocardial Infarction in Wistar Rats: Evidence from Biochemical and Histological Studies}

\author{
Bharath Kumar P, Mari Kannan M, Darlin Quine S' \\ Department of Clinical Pharmacy and Pharmacology, Jayamukhi College of Pharmacy, Narsampet, \\ Warangal, Andhra Pradesh, ${ }^{I}$ Government Arts College, C. Mutlur, Chidambaram, Tamilnadu, India
}

Address for correspondence: Mr. M. Mari Kannan; E-mail: mmkannan@in.com

\begin{abstract}
The present study was designed to evaluate the cardioprotective effects of methanolic extract of Litsea deccanensis (MELD) against isoproterenol-induced myocardial infarction in rats by studying cardiac markers, lipid peroxidation, lipid profile, and histological changes. Male Wistar rats were treated orally with MELD (100 and $200 \mathrm{mg} / \mathrm{kg}$ ) daily for a period of 21 days. After 21 days of pretreatment, isoproterenol $(100 \mathrm{mg} / \mathrm{kg}$ ) was injected subcutaneously to rats at an interval of $24 \mathrm{~h}$ for 2 days to induce myocardial infarction. Isoproterenol-induced rats showed significant $(P<0.05)$ increase in the levels of serum creatine kinase, lactate dehydrogenase, thiobarbituric acid reactive substances, and lipid hydro peroxides. The serum lipid levels were altered in the isoproterenol-induced myocardial infarcted rats. The histopathological findings of the myocardial tissue evidenced myocardial damage in isoproterenol-induced rats. The oral pretreatment with MELD restored the pathological alterations in the isoproterenol-induced myocardial infarcted rats. The MELD pretreatment significantly reduced the levels of biochemical markers, lipid peroxidation and regulated the lipid profile of the antioxidant system in the isoproterenol-induced rats. An inhibited myocardial necrosis was evidenced by the histopathological findings in MELD pretreated isoproterenol-induced rats. Our study shows that oral pretreatment with MELD prevents isoproterenol-induced oxidative stress in myocardial infarction. The presence of phenolic acid and flavonoid contents were confirmed by preliminary phytochemical tests. The reducing power and free radical scavenging activities of the MELD may be the possible reason for it pharmacological actions.
\end{abstract}

Key words: Antioxidant, infarct size, lipid metabolism, lipid peroxidation

\section{INTRODUCTION}

Recently, there has been a growing interest in establishing

\begin{tabular}{|l|l|}
\hline \multicolumn{2}{|c|}{ Access this article online } \\
\hline Quick Response Code: & \\
\hline & Website: \\
\hline & www.jyoungpharm.in \\
& \\
\hline
\end{tabular}

the therapeutic potentials of natural products against various diseases. Herbal medicine has been prescribed in many countries over centuries for treating various diseases, including infectious and malignant diseases. ${ }^{[1]}$ The use of plant products for medicinal purposes seems to be more natural, less expensive and without side effects. The therapeutic activities of plants are due to the presence of various active compounds like vitamins, flavonoids and polyphenols. The consumption of plant foods, such as antioxidant supplements or antioxidant-containing foods may be used to protect against various diseases, including 
cancer, cardio and cerebrovascular diseases ${ }^{[2]}$ Litsea is one of the most diverse genera of evergreen trees or shrubs belong to family Lauraceae. Plants belong to Litsea genus exhibit a variety of biological activities, including antimicrobial, hypothermic and anti-tumor activities. ${ }^{[3]}$ It has been reported the aphrodisiac activity of ethanolic extract of the bark of Litsea chinensis. ${ }^{[4]}$ The methanolic extract of Litsea cubeba and its fractions showed remarkable antioxidant activity in comparison with vitamin $\mathrm{E}$ and ascorbic acid. ${ }^{\left[{ }^{[}\right]}$ The leaves of Litsea decanensis are used as folk medicine for chest pain by tribal people in Andhra Pradesh state, India. Previous study from our laboratory explained the presence of phytochemical constituents present in Litsea decanensis and confirmed the presence of phenolic compounds. ${ }^{[6]}$ The GC--MS analysis and in vitro antioxidant activity of Litsea decanensis stimulated us to study the pharmacological efficacy of this plant against cardiovascular diseases.

Cardiovascular disease (CVD) is a major global health problem, reaching epidemic proportions in the Indian subcontinent. ${ }^{[7]}$ The majority of cardiovascular events such as myocardial infarction (MI) arise from individuals with unpretentious elevation of many etiological factors. ${ }^{[8]}$ Myocardial infarction (MI) is one of the leading causes of morbidity and mortality worldwide. MI occurs due to imbalance between myocardial blood supply and demand resulting in development of ischemia followed by necrosis. ${ }^{[9]}$ Reactive oxygen species (ROS) play an important role in oxidative stress and related myocardial damage. ROS-induced lipid peroxidation influence cardiac cell injury and affect the membrane integrity of cardio myocyte. Hyperlipidemia and hypertriglyceridemia have also been among the major reasons for the pathogenesis of MI. The current knowledge on the pathophysiology of MI stimulated the therapeutic intervention to reduce the risk of MI.

Isoproterenol [1-(3,4-dihydroxyphenyl)-2-isopropyl amino ethanol hydrochloride] (ISO) is a synthetic catecholamine and $\beta$-adrenergic agonist. The excess amount of ISO produces free radicals through its metabolites which are responsible for oxidative stress, and cardiac damage. The rat model of ISO-induced MI serves as a standard model to estimate the effect of cardio protective drugs in preclinical study and show many metabolic and morphologic alterations in the heart tissue of the experimental animals similar to those observed in human MI. ${ }^{[10]}$

\section{MATERIALS AND METHODS}

Plant collection and extraction

Litsea decanensis was collected during the month of
January from the forest regions of Chittoor district in Andhra Pradesh. The plant material was authenticated by Dr. Madava Chetty, Asst. Professor, Department of Botany, Sri Venkateshwara University, Tirupathi. A voucher specimen has been deposited in the Department of Pharmacognosy, Jayamukhi College of Pharmacy (Herbarium No.: 2-2010/Ph/JCP). The leaves were manually separated and dried at room temperature for $72 \mathrm{~h}$ then ground to a granulated powder using a grinder. The powdered leaves were extracted in a soxhlet extractor with petroleum ether $\left(60^{\circ} \mathrm{C}\right.$ for $\left.8 \mathrm{~h}\right)$ and defatted leaves powder was re-extracted in a soxhlet apparatus for $72 \mathrm{~h}$ with methanol at $60^{\circ} \mathrm{C}$. The methanolic extract of Litsea deccanensis (MELD) was allowed to dry and powdered.

\section{Chemicals}

Gallic acid and Isoproterenol were purchased from Sigma Chemical Co., St. Louis, MO, USA, Ascorbic acid, FolinCiocalteu reagent, 2,3,5-triphenyltetrazolium chloride, and rutin were purchased from Merck chemicals, India. All the other chemicals used were of the analytical grade.

\section{Determination of total phenolic content}

The content of total phenolic compound in MELD was determined by the method of Folin-Ciocalteu, 1927. ${ }^{[1]}$ All determinations were performed in triplicate. Total content of phenolic compounds of MELD in Gallic acid equivalents (GAE) was calculated by the following: $C=$ $c V / m$, where $C$ is the total content of phenolic compounds, $\mathrm{mg} / \mathrm{g}$ MELD, in GAE; $c$ is the concentration of gallic acid established from the calibration curve, $\mathrm{mg} / \mathrm{ml} ; V$ is the volume of MELD, $\mathrm{ml}$; and $m$ is the weight of MELD, $g$.

\section{Total flavonoid content}

The content of flavonoids was determined according to colorimetric method as described by Zou et al. ${ }^{[12]}$ In brief, $0.5 \mathrm{ml}$ of sample solution (MELD) was mixed with $2 \mathrm{ml}$ of distilled water and subsequently with $0.15 \mathrm{ml}$ of $5 \%$ $\mathrm{NaNO}_{2}$ solution. After 6 min of incubation, $0.15 \mathrm{ml}$ of $10 \% \mathrm{AlCl}_{3}$ solution was added and then allowed to stand for $6 \mathrm{~min}$, followed by adding $2 \mathrm{ml}$ of $4 \% \mathrm{NaOH}$ solution to the mixture. Immediately water was added to the sample to bring for another $15 \mathrm{~min}$. The mixture absorbance was determined at wavelength $510 \mathrm{~nm}$. The total flavonoid content was expressed in milligrams of rutin equivalents per gram of MELD. The amount of flavonoids in MELD in rutin equivalents (RE) was calculated by following formula: $X=\left(A m_{\mathrm{o}} 10\right) / A_{\mathrm{o}} m$, where $X$ is flavonoid content, $\mathrm{mg} / \mathrm{g}$ MELD in RE; $A$ is the absorption of MELD, $m_{\mathrm{o}}$ is 
the weight of rutin in the solution, $\mathrm{g} ; A_{\mathrm{o}}$ is the absorption of standard rutin solution; $m$ is the weight of MELD in $g$.

Determination of free radical scavenging activity by 2,2-diphenyl-1-picryl-hydrazyl

The free radical scavenging activities of various concentrations of MELD were measured in vitro by diphenyl-1-picryl-hydrazyl (DPPH) free radical scavenging assay. ${ }^{[13]}$ The percentage scavenging of the sample was calculated according to the equation: $\%$ Scavenging $=\left(A_{C^{-}}\right.$ $\left.A_{S} / A_{C}\right) \times 100$, where, $A_{C}$ is the absorbance of control, $A_{S}$ is the absorbance of sample, ascorbic acid, gallic acid, and used as control.

\section{Reducing power assay}

The total reducing power of MELD was determined according to method Oyaizu, 1986. ${ }^{[14]}$ Higher absorbance of the reaction mixture indicated greater reducing power.

\section{Experimental animals}

All the experiments were carried out with male albino Wistar rats (Rattus norvegicus) weighing 180--200 g, purchased from Mahaveer Enterprises, Hyderabad, India. They were housed in polypropylene cages $(47 \mathrm{~cm} \times 34$ $\mathrm{cm} \times 20 \mathrm{~cm}$ ) lined with husk, renewed every $24 \mathrm{~h}$ under a $12 \mathrm{~h} \mathrm{light/dark} \mathrm{cycle} \mathrm{at} 22 \pm 5{ }^{\circ} \mathrm{C}$ with $50 \%$ humidity. The animals were allowed to adapt to the new housing environment for 10 days before the experiment. They were provided with standard food pellets and water. All animal experiments were performed according to the guidelines of Committee for Purpose of Control and Supervision of Experiments on Animals (CPCSEA), New Delhi, India, approved by Institutional Animal Ethical Committee of Jayamukhi College of Pharmacy (Approval no: 17 , date 12-06-2010).

\section{Acute toxicity studies}

For acute toxicity studies, rats were divided into six groups of three animals in each group. MELD was dissolved in an appropriate volume of normal saline was administered orally at doses of 100, 200, 500, 1000, and $2000 \mathrm{mg} / \mathrm{kg}$ body weight/day for a period of 30 days. Same volume of normal saline without MELD was given to control group of animals. Morphological, behavioral, and toxic symptoms of the animals were also observed for 24,48 , and $72 \mathrm{~h}$ and the animals were weighed biweekly for the whole treatment period for delayed toxicity. MELD showed no lethal effect up to dose of $2000 \mathrm{mg} / \mathrm{kg}$ weight, indicating that $\mathrm{LD}_{50}$ if any should be higher than this dose. MELD was found to be safe at all the doses. Hence, $1 / 10^{\text {th }}$ and $1 / 20^{\text {th }}$ of the maximum safe dose corresponding to 200 and $100 \mathrm{mg} /$ $\mathrm{kg}$ orally were selected as high and low dose, respectively.

\section{Induction of myocardial infarction}

ISO was dissolved in normal saline and injected to rats $(100 \mathrm{mg} / \mathrm{kg})$ at an interval of $24 \mathrm{~h}$ for 2 days to induce experimental myocardial infarction. ${ }^{[15]}$ Animals were sacrificed $48 \mathrm{~h}$ after the first dose of ISO.

\section{Experimental design}

In our study, a total of 48 rats were used. They were divided into six groups of eight rats each. Two rats from each group were used for histological studies, i.e., 2,3,5-triphenyl tetrazolium chloride (TTC) staining technique and histopathological analysis. Remaining six animals in each group were used for biochemical analysis. Group I: normal control rats were given $2 \mathrm{ml}$ of saline orally by gastric incubation daily for a period of 21 days; Group II: normal rats were treated with MELD (100 mg/ $\mathrm{kg}$ ) in $2 \mathrm{ml}$ of saline orally by gastric incubation daily for a period of 21 days; Group III: normal rats were treated with MELD $(200 \mathrm{mg} / \mathrm{kg})$ in $2 \mathrm{ml}$ of saline orally by gastric incubation daily for a period of 21 days, Group IV: rats were subcutaneously injected with ISO $(100 \mathrm{mg} / \mathrm{kg})$ in $2 \mathrm{ml}$ of saline once a day for 2 days (on 22nd and 23rd day); Group V: rats were pretreated with MELD (100 mg/ $\mathrm{kg}$ ) in $2 \mathrm{ml}$ of saline orally by gastric incubation daily for a period of 21 days and then subcutaneously injected with ISO (100 mg/kg) once a day for 2 days (on $22^{\text {nd }}$ and $23^{\text {rd }}$ day); Group VI: rats were pretreated with MELD (200 $\mathrm{mg} / \mathrm{kg}$ ) in $2 \mathrm{ml}$ of saline orally by gastric incubation daily for a period of 21 days and then subcutaneously injected with ISO (100 mg/kg) once a day for 2 days (on 22nd and 23rd day). Twenty four hours after the second dose of ISO, rats of all the groups were anesthetized and sacrificed by cervical decapitation and blood was collected in two tubes, i.e., one with anticoagulant (ethylene diamine tetra acetic acid) for plasma separation, and another without anticoagulant for serum separation. Both the plasma and serum were separated from each sample and used for the biochemical analysis.

\section{Biochemical parameters}

The activities of creatine kinase $(\mathrm{CK})$, criatine kinase-MB fraction $(\mathrm{CK}-\mathrm{MB})$ and lactate dehyrogenase $(\mathrm{LDH})$ in the serum were determined by commercial diagnostic kits purchased from Accurex, Mumbai, India. The instructions 
from the manufacturer of the kits were followed. Thiobarbituric acid reactive substances (TBARS) in the plasma were measured by the method of Yagi. ${ }^{[16]}$ Lipid hydroperoxides $(\mathrm{LOOH})$ in the plasma was estimated by the method of Jiang et al. ${ }^{[17]}$

\section{Lipid profile}

Total cholesterol, high density lipoproteins (HDL) cholesterol, and triglycerides (TG) in the serum were measured by standard diagnostic kits (Accurex, Mumbai, India) according to the instruction given by the manufacturers. Very low density lipoproteins (VLDL) and low density lipoprotein (LDL) in the serum were calculated as per Friedewald et al. ${ }^{[18]}$ The level of free fatty acids (FFA) in the serum was estimated by the method of Falholt et al., ${ }^{[19]}$ and the level of phospholipids (PL) in the serum were estimated by the method of Zilversmit and Davis. ${ }^{[20]}$ The activity of 3-hydroxy-3 methyl glutryl CoA (HMG CoA) reductase in the liver tissue homogenate was assayed by the method of Rao and Ramakrishnan. ${ }^{[21]}$ Superoxide dismutase (SOD) activity in the plasma was assayed by the method of Kakkar et al. ${ }^{[2]}$ The activity of catalase in the plasma was assayed by the method of Sinha. ${ }^{[23]}$

Determination of myocardial infarction size by direct staining method

Myocardial infarction size was measured in the cardiac tissue by the method of Ojha et al. ${ }^{[2]}$ The slices were photographed after TTC staining.

\section{Histopathology}

Myocardial tissue after removal was immediately fixed in $10 \%$ buffered neutral formalin solution. After fixation was complete, tissues were embedded in paraffin and serial sections were cut. Each section was stained with hematoxylin and eosin. The sections were examined under light microscope $(45 \times)$ and photomicrographs were taken.

\section{Statistical analysis}

The results are expressed as mean \pm S.D. from six rats in each group. Statistical comparison between group by one-way analysis of variance (ANOVA) and a group by group comparison was performed by Duncan's multiple range test (DMRT). Differences between the groups were considered statistically at $P<0.05$.

\section{RESULTS}

Total phenolic and total flavonoid analysis

The total phenolic content and flavonoid content of MELD were measured in our study and found to be a notable concentration $0.2 \mathrm{mg} / \mathrm{ml}$ Gallic Acid equivalent and $2.26 \mathrm{mg} / \mathrm{g}$ of MELD in Rutin equivalents, respectively.

\section{Reducing power assay}

The reductive capabilities of MELD compared to rutin as shown in the Figure 1. The reducing power of MELD was very potent and the reducing power was increased with increase in the concentration of MELD. The MELD could reduce the most $\mathrm{Fe}^{3+}$ ions, which had a lesser reductive activity than the standard of rutin.

Free radical scavenging assay

DPPH (1,1-diphenyl-2-picryl-hydrazil) is a stable free radical that accepts an electron or hydrogen radical to become a stable diamagnetic molecule. ${ }^{[25]}$ Antioxidant activity of MELD studied by DPPH radical scavenging activity and the percentage scavenging activity increased with increase in the concentration of MELD [Figure 2].

Effect of MELD on levels of cardiac markers

The activities of serum CK, CK-MB, and LDH in normal and experimental rats were studied. The ISO-induced rats showed significant $(P<0.05)$ increase in the activities of $C K$, $\mathrm{CK}-\mathrm{MB}$, and $\mathrm{LDH}$ in the serum, when compared to normal control rats. Oral pretreatment with MELD $(100 \mathrm{mg} / \mathrm{kg}$ and $200 \mathrm{mg} / \mathrm{kg}$ ) daily for a period of 21 days reduced the levels of these enzymes in the serum, when compared to ISO-induced myocardial infarcted rats [Figure 3].

Effect of MELD on levels of TBARS and LOOH in heart

ISO-induced rats showed significant $(P<0.05)$ increase in the levels of plasma TBARS and $\mathrm{LOOH}$, when compared to normal control rats. Oral pretreatment with MELD $(100 \mathrm{mg} / \mathrm{kg}$ and $200 \mathrm{mg} / \mathrm{kg}$ ) daily for a period of 21 days inhibited the levels of these enzymes in the plasma, when compared to ISO alone treated rats [Figure 4].

Effect of MELD on levels of lipid profile

ISO-induced rats showed significant $(P<0.05)$ increase in the levels of total cholesterol, LDL, and VLDL. The decreased levels of HDL in the plasma were also observed. 


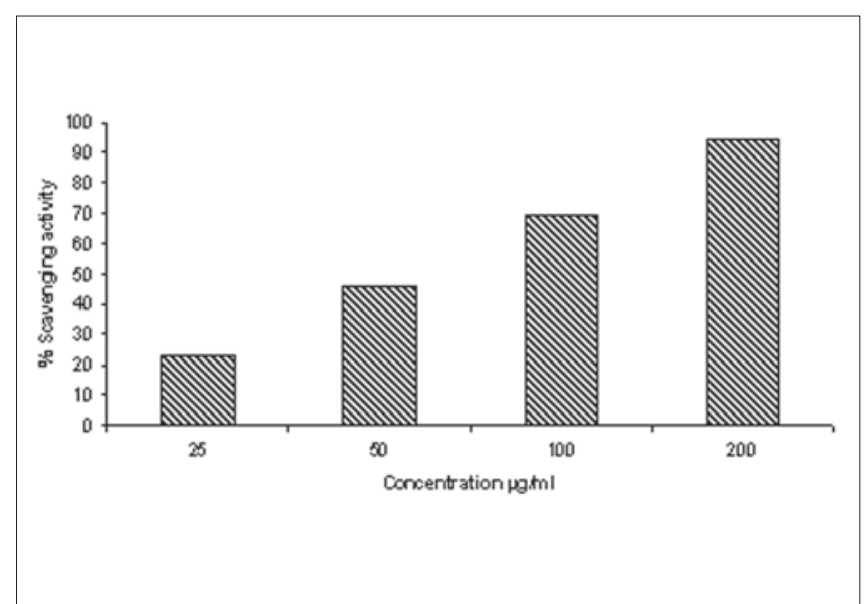

Figure 1: Reducing power of MELD

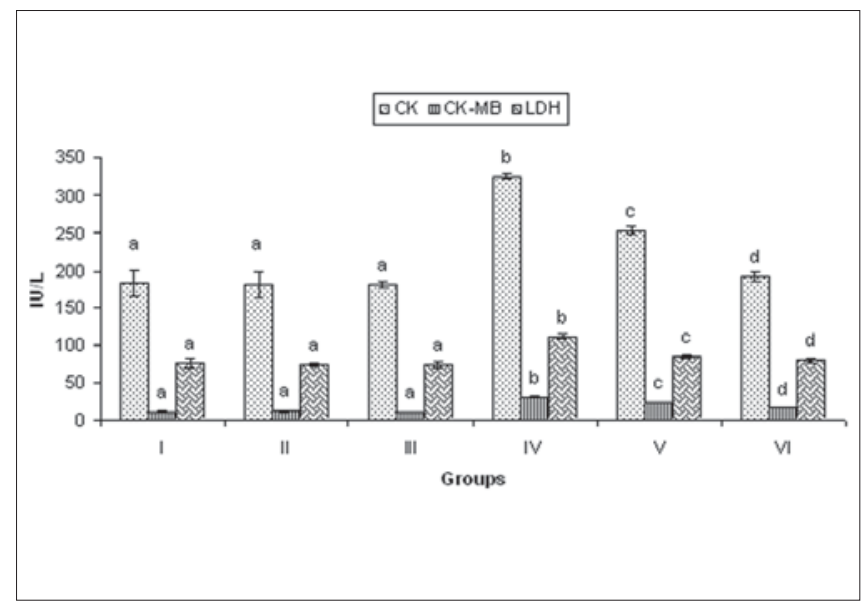

Figure 3: Effect of MELD on cardiac markers. Values are expressed as mean \pm standard deviation from six animals in each group. Significant $(P<0.05)$ compared to normal

Oral pretreatment with MELD (100 mg/kg and $200 \mathrm{mg}$ / $\mathrm{kg}$ ) daily for a period of 21 days significantly reduced total cholesterol, LDL, VLDL, and increased HDL [Figure 5].

\section{Estimation of MELD on levels of TG, FFAs, PLs}

Rats induced with ISO showed significant $(P<0.05)$ increase in the levels of TG, FFA, and PL in the serum, when compared to normal control rats. Oral pretreatment with MELD (100 mg/kg and $200 \mathrm{mg} / \mathrm{kg}$ ) daily for a period of 21 days normalized the activities of these enzymes in the serum, when compared to ISO alone treated rats [Figure 6].

\section{Effect of MELD on HMG CoA reductase activity}

ISO-induced rats showed significant $(P<0.05)$ increase in the activity of HMG CoA reductase in the liver tissue homogenate compared to normal control rats. Oral pretreatment with MELD (100 mg/kg and $200 \mathrm{mg} / \mathrm{kg}$ )

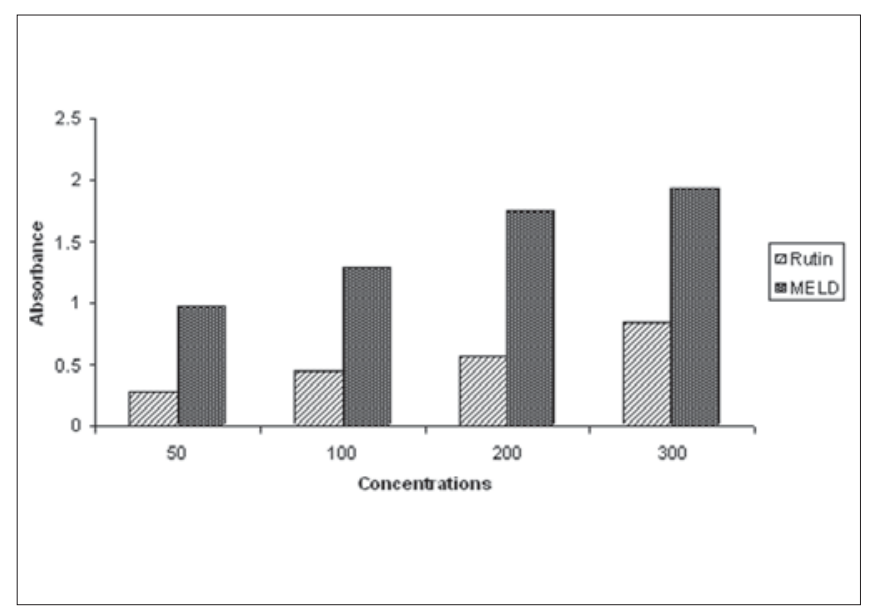

Figure 2: Scavenging activity of MELD against DPPH free radicals

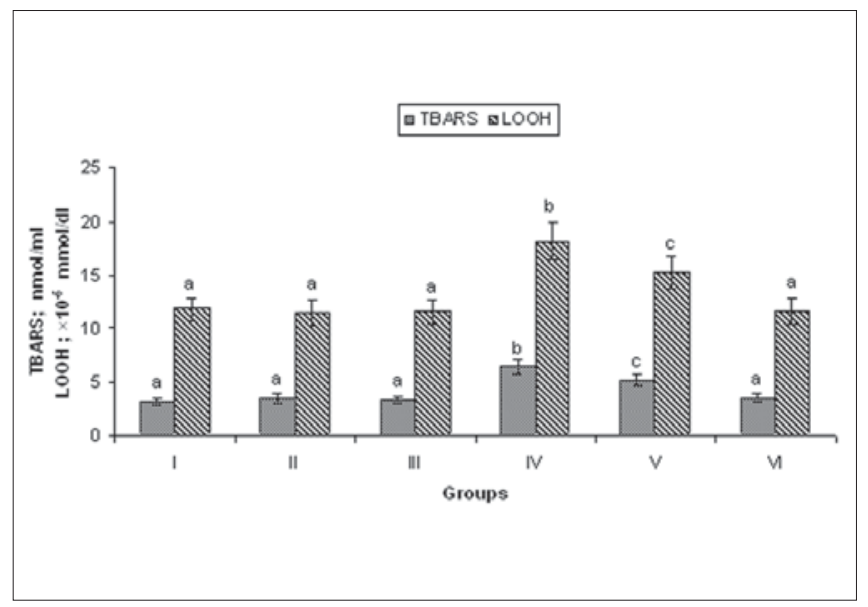

Figure 4: Effect of MELD on levels of lipid peroxidation products. Values are expressed as mean \pm standard deviation from six animals in each group. Significant $(P<0.05)$ compared to normal

daily for a period of 21 days reduced the activities of these enzymes in the serum compared to ISO-induced rat [Figure 7].

\section{Effect of MELD on antioxidant enzymes (SOD, catalase)}

ISO-induced rats showed significant $(P<0.05)$ decrease in the activities of SOD, catalase in the plasma compared to normal control rats. This result reflects the diminished antioxidant enzymes. Oral pretreatment with MELD $(100 \mathrm{mg} / \mathrm{kg}$ and $200 \mathrm{mg} / \mathrm{kg}$ ) daily for a period of 21 days significantly increase the activities of these enzymes in the plasma, when compared to ISO alone treated rats [Figure 8].

For all the biochemical parameters studied, pretreatment with MELD $(100 \mathrm{mg} / \mathrm{kg}$ and $200 \mathrm{mg} / \mathrm{kg})$ daily for a period of 21 days to the normal control rats did not show any significant effect. 


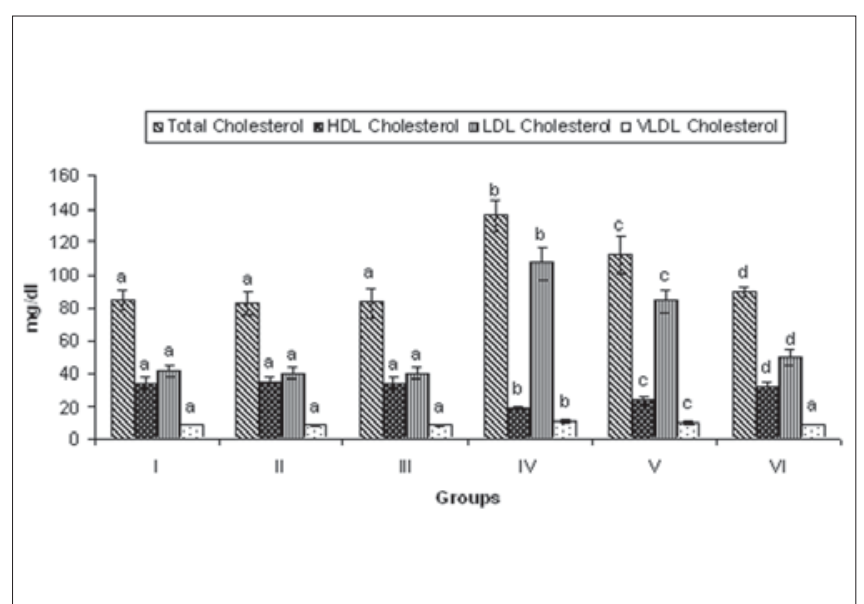

Figure 5: Effect of MELD on levels of lipids and lipoproteins. Values are expressed as mean \pm standard deviation from six animals in each group. Significant $(P<0.05)$ compared to normal

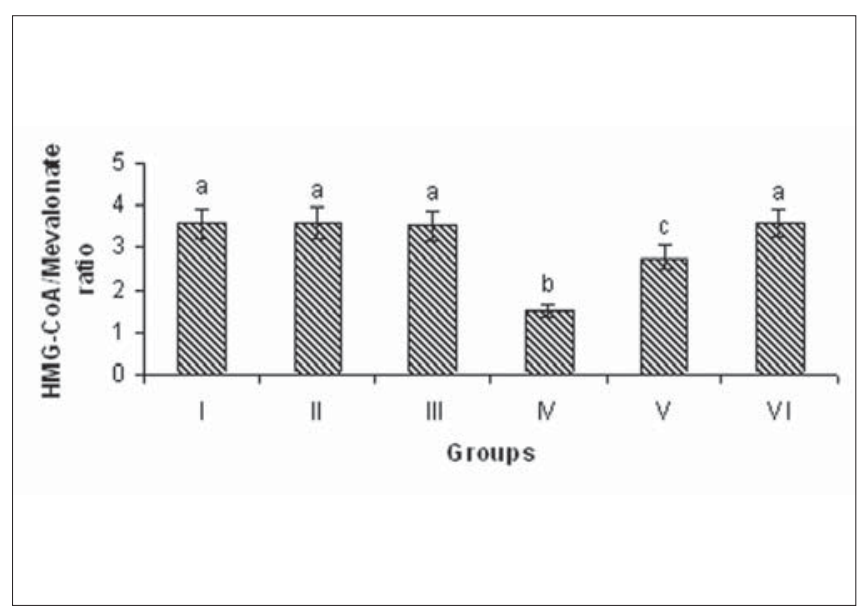

Figure 7: Effect of MELD on the activity of HMG-CoA in the liver. Values are expressed as mean \pm standard deviation from six animals in each group. Significant $(P<0.05)$ compared to normal

\section{Quantification of myocardial infarct size}

Detection of myocardial infarct size by direct staining method using 2,3,5- triphenyltetrazolium chloride (TTC) dye, which forms a red formazan precipitate with dehydrogenase of the viable myocardial tissue shows normal viable tissue with red color/dark spot. ISO-induced rats clearly showed the infarct region by pale yellow color/ bright spot. The oral pretreatment with MELD (100 mg/ $\mathrm{kg}, 200 \mathrm{mg} / \mathrm{kg}$ ) markedly reduced the infarcted size in ISO-induced rats [Figure 9].

\section{Histopathology}

The ISO-induced rats showed the evidence of myocardial necrosis, tissue damage, infiltration of inflammatory cells and hemorrhage. The rats received MELD $(100 \mathrm{mg} / \mathrm{kg}$ and $200 \mathrm{mg} / \mathrm{kg}$ ) as oral pretreatment showed decreased necrosis, less tissue damage and reduced infiltration of

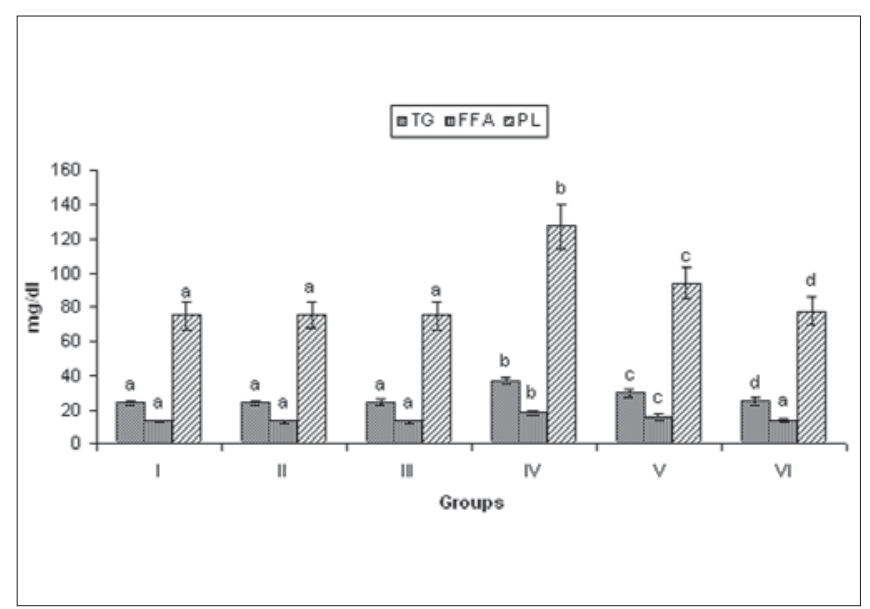

Figure 6: Effect of MELD on levels of TG, FFA, and PL. Values are expressed as mean \pm standard deviation from six animals in each group. Significant $(P<0.05)$ compared to normal

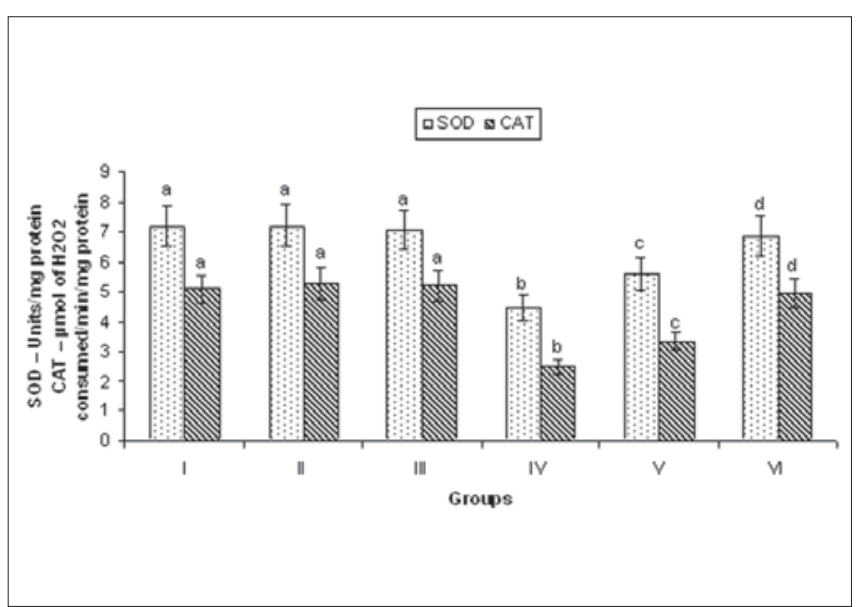

Figure 8: Effect of MELD on the activities of SOD and CAT. Values are expressed as mean \pm standard deviation from six animals in each group. Significant $(P<0.05)$ compared to normal

inflammatory cells, when compared to ISO-induced myocardial infarcted rats [Figure 10]. The quantification of histological damage was mentioned in Table 1.

\section{DISCUSSION}

The phytochemical analysis of MELD confirmed the presence of phenolic contents and particularly flavonoids. High phenolic compounds may cause the anti-oxidative activities of this plant. ${ }^{[26]}$ The beneficial effect of polyphenols is associated with a multitude of biological activities, including antioxidant and free radical-scavenging properties, anti-platelet aggregation and inhibition of vascular smooth muscle cell proliferation. ${ }^{[27]}$ Our study suggested that the presence of phenolic and flavonoid content and its free radical scavenging action of MELD.

Isoproterenol is a potent, nonselective $\beta$-receptor agonist. 
Table 1: Quantitative evaluation of histopathological study

\begin{tabular}{|c|c|c|c|c|c|c|}
\hline Groups & Normal & $\begin{array}{c}\text { MELD } \\
(100 \mathrm{mg} / \mathrm{kg})\end{array}$ & $\begin{array}{c}\text { MELD } \\
(200 \mathrm{mg} / \mathrm{kg})\end{array}$ & ISO & $\begin{array}{c}\text { MELD } \\
(100 \mathrm{mg} / \mathrm{kg})+\text { ISO }\end{array}$ & $\begin{array}{c}\text { MELD } \\
(200 \mathrm{mg} / \mathrm{kg})+\text { ISO }\end{array}$ \\
\hline Cardiac muscle separation & - & - & - & +++ & + & - \\
\hline Broken cardiac fibers & - & - & - & +++ & - & - \\
\hline Hemorrhage & - & - & - & +++ & ++ & + \\
\hline $\begin{array}{l}\text { Mononuclear inflammatory infiltrate in } \\
\text { cardiac tissue }\end{array}$ & - & - & - & +++ & ++ & - \\
\hline
\end{tabular}

$(-)$ absence; $(+)$ mild; $(++)$ moderate; $(+++)$ severe

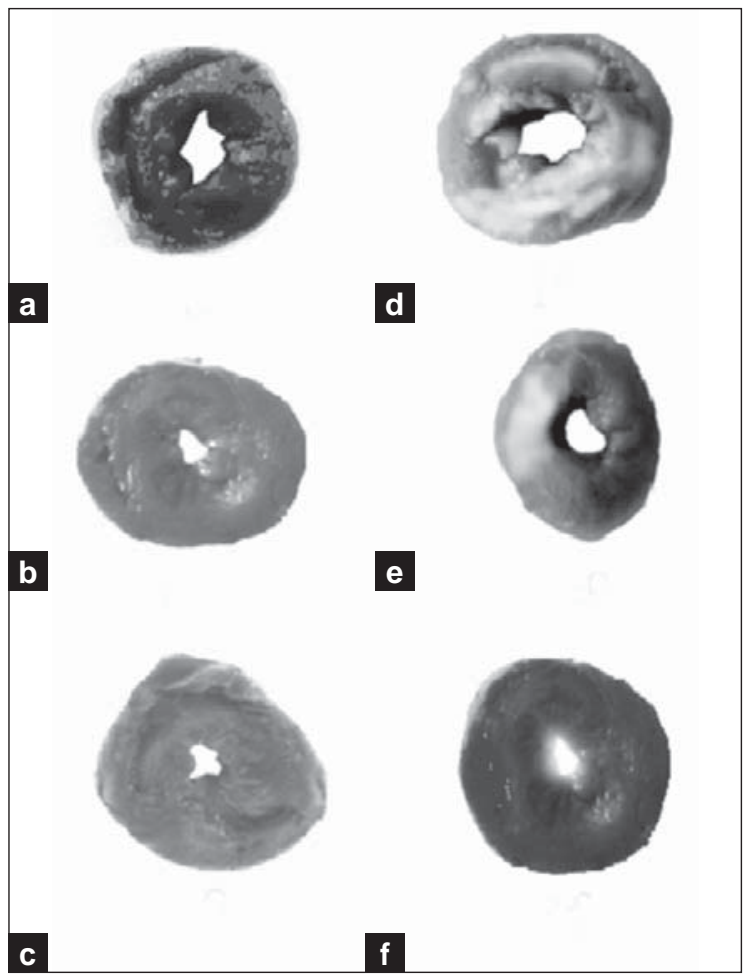

Figure 9: Myocardial infarct size quantification assay (a) Heart slice showing viable cells in normal control group. (b) Heart slice of MELD $(100 \mathrm{mg} / \mathrm{kg})$ treated rats showing no significant change from the normal control group. (c) Heart slice of MELD (200 mg/kg) treated rats also showed no significant change. (d) Heart slice of ISO-induced showed increased infarct size and indicating non-viable cells. (e) Heart slice of MELD (100 mg/kg) pretreated and ISO-induced rat showing less infarct size than ISO-induced group. (f) Heart slice of MELD (200 $\mathrm{mg} / \mathrm{kg}$ ) pretreated and ISO-induced rat showing further reduced infarct size, when compared to (d) and (e).

ISO metabolized by Catechol-O-methyl transferase, and excessive dose can produce cardiac ischemia, sympathetic hyper activation and leads to myocardial tissue damage. The metabolic products of ISO are responsible for the production of free radical and myocardial damage in ISOinduced rats. The myocardium is having abundance of enzymes and these enzymes serve as diagnostic marker for cardiovascular diseases. When myocardial cells are damaged, the cardiac membrane integrity will be affected and released these enzymes into the systemic circulation. The significant increase in the levels of cardiac markers in ISO-induced rats is an indication of the severity of necrotic damage in the myocardium induced by ISO. Oral pretreatment with

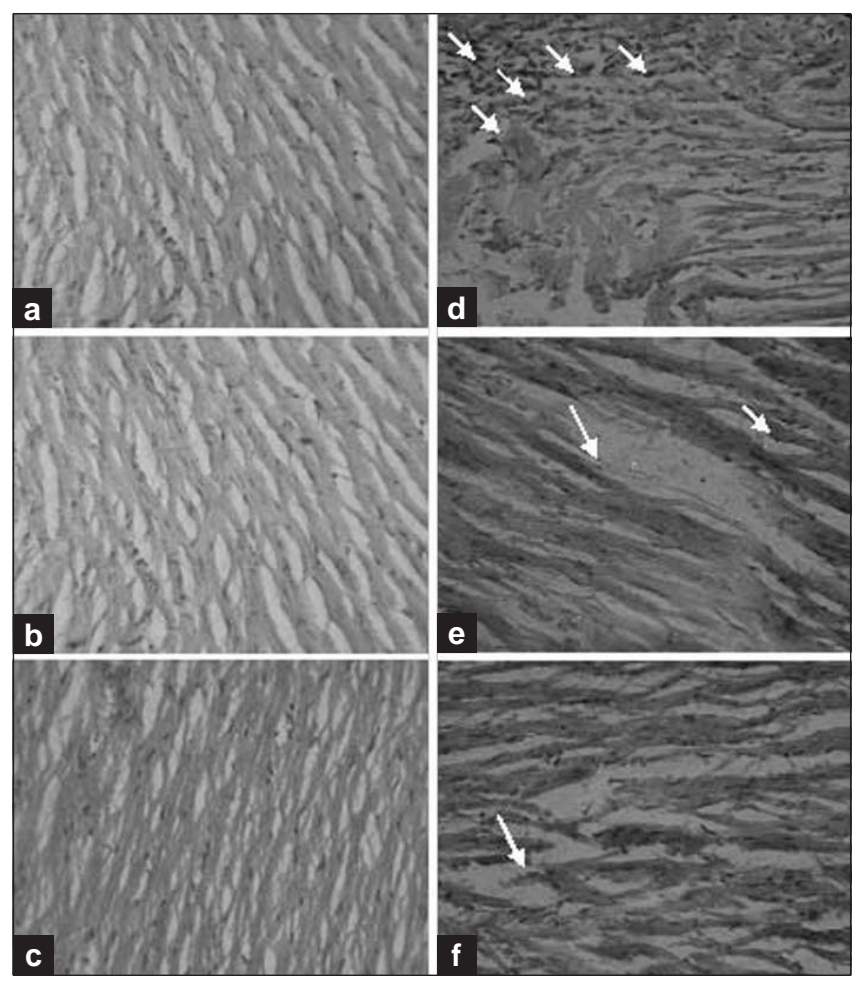

Figure 10: Histopathology of the heart tissue of normal and experimental groups of rats. (a) Section of heart tissue from normal control rat showing normal architecture of heart tissue. (b) Section of heart tissue of MELD (100 mg/kg) treated rats showing no significant change from the normal architecture. (c) Section of heart tissue of MELD $(200 \mathrm{mg} / \mathrm{kg}$ ) treated rats also showing nearly normal architecture. (d) Section of heart tissue of ISO-induced rats showed necrotic damage, infiltration of neutrophils and altered structure of myofiber. (e) Section of heart tissue of MELD (100 mg/kg) pretreated and ISO-induced rat showing mild focal degenerative changes in the cardiac muscle fiber. (f) Section of heart tissue of MELD (200 mg/kg) pretreated and ISO-induced rat showing almost normal architecture.

MELD $(100 \mathrm{mg} / \mathrm{kg}, 200 \mathrm{mg} / \mathrm{kg})$ significantly $(P<0.05)$ reduced the levels of cardiac markers in the serum of ISOinduced rats, and it is indicating the membrane stabilizing effect of MELD.

Lipid peroxidation is an important pathogenic event that damage myocardial membrane. Increased lipid peroxidation is thought to be a consequence of oxidative stress which occurs when the dynamic balance between pro-oxidant and antioxidant mechanism is impaired. ${ }^{[28]}$ The degree of lipid peroxidation in the normal and experimental was 
estimated by measuring TBARS, LOOH in normal and experimental rats. ISO-induced rats showed increased levels of lipid peroxidation products (TBARS and LOOH) in the plasma. Our results are in consistent with previous reports. ${ }^{\left[{ }^{[2]}\right]}$ MELD pretreatment $(100 \mathrm{mg} / \mathrm{kg}, 200 \mathrm{mg} / \mathrm{kg}$ ) decreased the levels of TBARS, LOOH in ISO-induced rats. This anti-lipid peroxidation effect of MELD may be responsible for its membrane stabilizing effect.

Cardiovascular diseases are clearly associated with Dyslipidemia and dyslipoproteinemia. ${ }^{[30,31]}$ An altered lipid metabolism can alter the cardiac function by changing the properties of cardiac cell membrane and these changes may contribute to the cell death. We observed the increased levels of total cholesterol, LDL and VLDL and decreased level of HDL in the serum of ISO-induced rats. These changes in lipid levels might be due to enhanced lipid biosynthesis by cardiac cyclic adenosine monophosphate. High levels of LDL cholesterol show a positive correlation with myocardial infarction, whereas HDL cholesterol has a negative correlation. ${ }^{[32]}$ The oral administration of MELD reduced the levels of LDL and increases the levels of HDL in ISO-induced rats. These results show its positive impact against dyslipidemia. Clinical trails support lipid lowering therapy to minimize the risk of cardiovascular diseases. Thus, MELD pretreatment can be considered to reduce the risk of cardiovascular diseases.

Hypertriglyceridemia is one of the major pathological conditions related to MI. We observed an increased level of TG in the serum of ISO-induced rats and it might be due to decreased activity of lipoprotein lipase, and decreased uptake of TG from the circulation. A significant increase in free fatty acid and phospholipids in the serum of ISO-induced rats were also observed. The breakdown of membrane phospholipids, by the free radicals produced by ISO metabolites, the increased peroxidation of membrane phospholipids by releases free fatty acids by the action of phospholipase $\mathrm{A}_{2}$ are the reasons for increased phospholipids. ${ }^{[3]}$ Oral pretreatment with MELD (100 mg/ $\mathrm{kg}$ and $200 \mathrm{mg} / \mathrm{kg})$ significantly $(P<0.05)$ decreased the levels of phospholipids and free fatty acids in the serum of ISO-induced rats. The effect of MELD in the reduced levels of FFA and PL reflected its protective action against PL rich myocardial membrane. The findings are supporting its beneficial effect on lipid metabolism.

Most of drugs acting on dyslipidemia are the HMG CoA reductase inhibitors. HMG CoA reductase catalysis the conversion of HMG CoA to mevalonate and the inhibition of this conversion is the rate limiting step in cholesterol biosynthesis. Our results indicated that the pretreatment with MELD showed beneficial effect on dyslipidemia. Phytochemicals those showed beneficial effects on dyslipidemia have inhibited HMG CoA reductase in the animal models. ${ }^{[34,35]}$ We hypothesized that the inhibiting effect of MELD on dyslipidemia in the ISO-induced rats may be due to its inhibiting character on HMG CoA reductase. To confirm this action we studied the ability of MELD on HMG CoA/mevalonate ratio. HMG CoA reductase plays a major role in the regulation of cholesterol metabolism and a rate limiting enzyme in the pathway of cholesterol biosynthesis. ${ }^{[2]}$ The significant increased in the activity of HMG CoA reductase in the liver of ISOinduced rats was observed by decrease ratio between $\mathrm{HMG}$ $\mathrm{CoA}$ and mevalonate. An increased HMG CoA reductase activity leads to excessive biosynthesis of cholesterol and accumulation of cholesterol in the cardiovascular system which may lead to atherosclerosis, myocardial necrosis and infarction. Pretreatment with MELD $(100 \mathrm{mg} / \mathrm{kg}, 200$ $\mathrm{mg} / \mathrm{kg}$ ) significantly reduced the activity of HMG CoA reductase in ISO-induced rats and indicated by significantly increased ratio of HMG CoA and mevalonate. This might be one of the reasons for the beneficial effect of MELD on lipid and lipoprotein metabolism.

The supramaximal dose of ISO produce free radicals and generation of ROS affect the balance between cellular antioxidant defense and free radicals. Antiperoxidative enzymes such as SOD and catalase are the first line cellular defense antioxidant enzymes against oxidative stress. We observed decrease in the activities of SOD and catalase in ISO-induced rats. The enhanced lipid peroxidation and increased generation of ROS such as superoxides and hydrogen peroxides. These free radicals utilized the endogenous antioxidant enzymes SOD and catalase and make the myocardium more susceptible for further free radical attack. Oral pretreatment with MELD $(100 \mathrm{mg} / \mathrm{kg}$, $200 \mathrm{mg} / \mathrm{kg}$ ) increased the levels of SOD, catalase in the heart tissue and demonstrate its antioxidant effect.

TTC is a redox indicator commonly used in biochemical experiments to differentiate between metabolically active and inactive cells and tissues. The presence of electron donor NADH favors oxidation of TTC into 1,3,5-triphenylformazan TPF. In the cell death, the NADH decreases and prevents the oxidation of TTC to TPF. ${ }^{[36]}$ The presence of NADH and dehydrogenase enzymes (i.e., succinate dehydrogenase and lactate dehydrogenates) will convert the TTC in to TPF which shows red color spots in viable myocardial tissue. In the present study we observed an increased infarct size which is indicated by a clear bright/ yellow color spot in the heart slices of ISO-induced rats. The utilization of NADH by the free radicals produced 
by ISO and leakage of dehydrogenase enzymes from the damaged myocardial cells are the possible mechanisms that might prevented the conversion of TTC in to TPF. This may be the reason for the colorless bright spot in ISOinduced rat heart and reflects the presence of non viable cells. This finding was also supported by the increased levels of $\mathrm{LDH}$ in the serum of ISO-induced rats, where $\mathrm{LDH}$ might release out from the myocardium. Oral pretreatment with MELD (100 mg/kg, $200 \mathrm{mg} / \mathrm{kg})$ markedly reduce the infarcted size in ISO-induced rats. The antioxidant and membrane stabilizing activity of MELD could be the possible reason for reduction in the myocardial infarct size.

To further confirm the beneficial effect of MELD, histopathological study was performed on normal and experimental animals. The results showed a better insight of cardio protective effect of MELD. The normal heart showed no change in the architecture of myocardial tissue. The rats pretreated with MELD (100 mg/kg, $200 \mathrm{mg} /$ $\mathrm{kg}$ ) also showed the similar architecture as normal heart. The ISO-induced rats showed the evidence of myocardial necrosis, tissue damage, infiltration of inflammatory cells and hemorrhage. The rats received MELD (100 mg/kg) as oral pretreatment showed decreased necrosis, less tissue damage and reduced infiltration of inflammatory cells. The rats pretreated with MELD $(200 \mathrm{mg} / \mathrm{kg}$ ) further reduced the pathological changes and brings back the cellular architecture almost similar to the normal.

The reducing power and free radical scavenging activity of MELD were studied to confirm the mechanism action of MELD in vitro showed better reducing power than the standard compound rutin. The in vitro study results confirmed the possible antioxidant activity by MELD.

In conclusion, our results of the present study indicate that the oral pretreatment with MELD reduced the cardiac marker levels in the serum of ISO-induced rats. MELD also showed anti lipid peroxidative effect and regulated the altered lipid metabolism in the ISO-induced rats. The improvement in the activities of SOD and catalase in the ISO-induced rats showed the antioxidant potentials of MELD. The histological study by infarct size quantification assay and histo-architectural analysis of the myocardium confirmed the cardioprotective effect of MELD at various doses. Our in vitro analysis of antioxidant activity against DPPH free radicals confirmed the scavenging effect of MELD. This could be the possible mechanism of MELD against the ISO-induced pathological events of MI in rats.

\section{ACKNOWLEDGMENTS}

The authors P. Bharath Kumar and M. Mari Kannan are grateful to T.V.R.N. Reddy, Joint Secretary, Jayamukhi Institutions for his constant support and encouragement during the research work; Dr. S. Vasudeva Murthy, Principal, Jayamukhi College of Pharmacy, for his valuable suggestions to improve the plan of research.

\section{REFERENCES}

1. Samarghandian S, Boskabady MH, Davoodi S. Use of in vitro assays to assess the potential antiproliferative and cytotoxic effects of saffron (Crocus sativus L.) in human lung cancer cell line. Pharmacogn Mag 2010;6:309-14.

2. Ozen T, Turkeku I. Antioxidant activities of Sarcodon imbricatum wildly grown in the black sea region of Turkey. Pharmacogn Mag 2010;6:89-97.

3. Xiao-dong Y, Li-juan Y, Shu Y, Jing-feng Z, Hong-bin Z, Liang Li. Flavonoids from Litsea chingpingensis. Chem Nat Comp 2008;44:642-3.

4. Ageel AM, Islam MW, Ginawi OT, Al-Yahya MA. Evaluation of the aphrodisiac activity of Litsea chinensis (Lauraceae) and Orchis malculata (Orchidaceae) extracts in rats. Phytother Res 2000;8:103-5.

5. Hwang HK, Choi EM, Lee JH. Antioxidant activity of Litsea cubeba. Fitoterapia 2005;76:684-6.

6. Bharath Kumar P, Mari Kannan M, Lavanya B, Suthakaran R, Darlin Quine S. GC-MS analysis of methanolic extract of Litsea decanensis gamble and its free radical scavenging activity. J Pharm Res 2011;4:100-3.

7. Banerjee A. Coronary artery disease and its problems in management. J Indian Med Assoc 2001;9:474-5.

8. Goenka S, Prabhakaran D, Ajay VS, Reddy KS. Preventing cardiovascular disease in India -Translating evidence to action. Curr Sci 2009;97:367-77.

9. De Bono DP, Boon NA. Diseases of the cardiovascular system. In: Edwards CR, Boucheir IA, editors. Davidson's principles and practice of medicine. Hong Kong: Churchill Livingstone;2002 p. 249-340.

10. Nirmala C, Anand A, Puvanakrishnan R. Protective role of curcumin against isoproterenol induced myocardial infarction in rats. Mol Cell Biochem 1996;159:85-93.

11. Folin O, Ciocalteu V. On tyrosine and tryptophane determination in proteins. J Biol Chem 1927;27:627-50.

12. Zou Y, Lu Y, Wei D. Antioxidant activity of a flavonoid rich extract of Hypericum perforatm L. in vitro. J Agric Food Chem 2004;52:5032-9.

13. Blois MS. Antioxidant determinations by the use of a stable free radical. Nature 1958;181:1199-200.

14. Oyaizu M. Studies on product of browning reaction prepared from glucose amine. Jpn J Nutr 1986;44:307-15.

15. Punithavathi VR, Prince PS. Combined effect of Quercetin and alpha tocopherol on lipids and glycoprotein components in isoproterenol induced wistar rats. Chem Biol Interact 2009;181:322-7.

16. Yagi K. Lipid peroxides and human diseases. Chem Phys Lipids 1987;45:337-51.

17. Jiang ZY, Hunt JV, Wolff SP. Ferrous ion oxidation in the presence of xylenol orange for detection of lipid hydroperoxide in low density lipoprotein. Anal Biochem 1992;202:384-9.

18. Friedewald WT, Levy RI, Fredrickson DS. Estimation of the concentration of low density lipoprotein cholesterol in plasma, without use of the preparative ultracentrifuge. Clin Chem 1972;18:499-502.

19. Falholt K, Lund B, Falholt W. An easy colorimetric micromethod for routine determination of free fatty acids in plasma. Clin Chim Acta 1973;46:105-11.

20. Zilversmith DB, Davis AK. Micro determination of plasma phospholipids by trichloroacetic acid precipitation. J Lab Clin Med 1950;35:155-60.

21. Rao AV, Ramakrishnan S. Indirect assessment of HMG CoA reductase (NADPH) activity in liver tissue. Clin Chem 1975;21:1523-5.

22. Kakkar P, Das B, Viswanathan PN. A modified spectrophotometric assay of superoxide dismutase. Indian J Biochem Biophys 1984;21:130-2.

23. Sinha AK. Colorimetric assay of catalase. Anal Biochem 1972;47:389-94.

24. Ojha N, Roy S, Radtke J, Simonetti O, Gnyawali S, Zweier JL. 
Characterization of the structural and functional changes in the myocardium following focal ischemia-reperfusion injury. Am J Physiol Heart Circ Physiol 2008;294:H2435-43.

25. Bhujbal SS, Kewatkar SM, More LS, Patil MJ. Antioxidant effects of roots of Clerodendrum serratum Linn. Pharmacogn Res 2009;1:294-8.

26. Ebrahimzadeh MA, Ehsanifar S, Eslami B. Sambucus ebulus elburensis fruits: A good source for antioxidants. Pharmacogn Res 2009;5:213-8.

27. Ramchoun M, Harnafi H, Alem C, Benlyas M, Elrhaffari L, Amrani S. Study on antioxidant and hypolipidemic effects of polyphenol-rich extracts from Thymus vulgaris and Lavendula multifida. Pharmacogn Res 2009;1:106-12.

28. Kumari SS, Menon VP. Changes in levels of lipid peroxides and activities of superoxide dismutase and catalase in isoproterenol induced myocardial infarction in rats. Indian J Exp Biol 1987;25:419-23.

29. Prince PS, Sathya B. Pretreatment with quercetin ameliorates lipids, lipoproteins and marker enzymes of lipid metabolism in isoproterenol treated cardiotoxic male Wistar rats. Eur J Pharmacol 2010;635:142-8.

30. Fuster V, Gotto AM Jr. Risk reduction. Circulation 2000;102:IV94-102.

31. Freedman DS, Otvos JD, Jeyarajah EJ, Shalaurova I, Cupples LA, Parise $\mathrm{H}$, et al. Sex and age differences in lipoprotein subclasses measured by nuclear magnetic resonance spectroscopy: The Framingham study. Clin Chem 2004;50:1189-200.

32. Buring JE, O’Connor GT, Goldhaber SZ, Rosner B, Herbert PN, Blum CB, et al. Decreased HDL-2 and HDL-3 cholesterol, APO A-11 and increased risk of myocardial infarction. Circulation 1992;85:22-9.

33. Nalbone G, Grynberg A, Chevalier A, Leonardi J, Termine E, Lafont H. Phospholipase A activity of cultured rat ventricular myocyte is affected by the nature of cellular polyunsaturated fatty acids. Lipids 1990;25:301-6.

34. Devika PT, Stanely Mainzen Prince P. Protective effect of (-) epigallocatechin gallate (EGCG) on lipid peroxide metabolism in isoproterenol induced myocardial infarction in male Wistar rats: A histopathological study. Biomed Pharmacother 2008;62:701-8.

35. Devipriya N, Sudheer AR, Vishwanathan P, Menon VP. Modulatory potential of ellagic acid, a natural plant polyphenol on altered lipid profile and lipid peroxidation status during alcohol-induced toxicity: A pathohistological study. J Biochem Mol Toxicol 2008;22:101-12.

36. Csonka C, Kupai K, Kocsis GF, Novák G, Fekete V, Bencsik P, et al. Measurement of myocardial infarct size in preclinical studies. J Pharmacol Toxicol 2010;61:163-70.

How to cite this article: Kumar PB, Kannan MM, Quine SD. Litsea deccanensis ameliorates myocardial infarction in wistar rats: Evidence from biochemical and histological studies. J Young Pharmacists 2011;3:287-96.

Source of Support: Nil, Conflict of Interest: None declared.

Announcement

\section{"Quick Response Code" link for full text articles}

The journal issue has a unique new feature for reaching to the journal's website without typing a single letter. Each article on its first page has a "Quick Response Code". Using any mobile or other hand-held device with camera and GPRS/other internet source, one can reach to the full text of that particular article on the journal's website. Start a QR-code reading software (see list of free applications from http://tinyurl.com/ yzlh2tc) and point the camera to the QR-code printed in the journal. It will automatically take you to the HTML full text of that article. One can also use a desktop or laptop with web camera for similar functionality. See http://tinyurl.com/2bw7fn3 or http://tinyurl.com/3ysr3me for the free applications. 